\title{
List of Plates
}

1. L'Explication (1952)

2. La Condition humaine (1935)

3. Ceci n'est pas une pipe (1926)

4. Les Deux mystères (1966)

5. Tombeau des lutteurs (1960)

6. La Bataille de l'Argonne (1959)

7. "Fumées," by Guillaume Apollinaire

8. "L'Oeillet," by Guillaume Apollinaire

9. Paul Klee, Villa $R$ (1919)

10. Paul Klee, The Wild Man (1922)

11. Wassily Kandinsky, White Balancing (1944)

12. Wassily Kandinsky, Improvisation: Green Center (1935)

13. L'Incendie (1943)

14. Le Séducteur (1950)

15. La Philosophie dans le boudoir (1947)

16. L'Art de la conversation (1950)

17. Le Soir qui tombe (1934)

18. Personnage marchant vers l'horizon (1928-29)

19. L'Alphabet des révélations (1935)

20. Perspective: Mme. Récamier (1958)

21. L'Usage de la parole (1932)

22. Représentation (1962)

23. Décalcomanie (1966)

24. Les Grâces naturelles (1962)

25. La Dame, painted bottle (1943) 
26. Folie des grandeurs (1961)

27. La Condition humaine (1933)

28. La Cascade (1961)

29. La Lunette d'approche (1963)

30. Les Liaisons dangereuses (1936) 